\title{
Mediastinal Malignant Peripheral Nerve Sheath Tumor
}

National Cancer Institute

\section{Source}

National Cancer Institute. Mediastinal Malignant Peripheral Nerve Sheath T umor. NCI

Thesaurus. Code C6626.

A malignant peripheral nerve sheath tumor that arises from the mediastinum. It may be associated with neurofibromatosis. It often spreads to the lungs or pleura. 